Tropical Journal of Pharmaceutical Research August 2012; 11 (4): 585-594

(c) Pharmacotherapy Group, Faculty of Pharmacy, University of Benin Benin City, 300001 Nigeria.

All rights reserved.

Available online at http://www.tjpr.org

Research Article

http://dx.doi.org/10.4314/tjpr.v11i4.9

\title{
A Comparative Study of the Compaction Properties of Binary and Bilayer Tablets of Direct Compression Excipients
}

\author{
Mohd Cairul Iqbal Mohd Amin*, Sami Mohammed Albawani and \\ Muhammad Wahab Amjad \\ Faculty of Pharmacy, Universiti Kebangsaan Malaysia, Jalan Raja Muda Abdul Aziz, 50300, Kuala Lumpur, Malaysia
}

\begin{abstract}
Purpose: To comparatively evaluate the tableting properties of binary mixtures and bilayer tablets containing plastic deformation and brittle fracture excipients.

Methods: Binary mixture and bilayer tablets of microcrystalline cellulose (MCC), ethyl cellulose, anhydrous lactose and dextrate were prepared by direct compression and the effect of compaction pressure on the materials was investigated by scanning electron microscopy (SEM). True, bulk and tap densities of excipients were determined. Furthermore, Heckel equation and Carr's index were used to analyze the compression behaviour of the tablets.

Results: The flowability of dextrate, based on Heckel and Carr's Index data, was superior to that of other powder excipients tested. No significant difference was observed between the tensile strength of binary and bilayer tablets of the same composition. However, the tensile strength of binary and bilayer tablets of different compositions varied significantly $(p<0.001)$, e.g., the tensile strength of microcrystalline cellulose (MCC)/ethyl cellulose (EC) tablets (50/50) was $1.77 \mathrm{MPa}$ while that of $\mathrm{MCC} /$ dextrate at 50/50 composition was $1.47 \mathrm{MPa}$.

Conclusion: Binary mixture and bilayer tablets show similar behaviour when formulated using excipients of similar deformation properties. However, their behavior changes when excipients with different deformation properties are blended together.
\end{abstract}

Keywords: Binary mixture, Bilayer tablet, Brittle fracture, Plastic deformation, Tensile strength. 


\section{INTRODUCTION}

In 2008, among various dosage forms in medicine, tablets still account for $80 \%$ of the drug delivery systems administered to human [1]. Tablets are produced by applying a certain compression pressure on a bed of powder. Normally, a tablet contains a combination of two or more powders to obtain a compact with the desired properties. Direct compression is still the method of choice for the manufacture of tablets where the components are mixed together before they are compressed directly into tablets [2]. In addition to active pharmaceutical ingredient, various excipients are also important for production of elegant tablets with desired mechanical strength, disintegration and dissolution time. These include antiadherents, binders, enterics, disintegrants, fillers, flavours, colours, lubricants, glidants, sorbents, preservatives and sweeteners. Amongst all, one of the most important function of excipients is to enhance the tablet strength. Therefore, most of the studies on direct compression technique are concerned with the compaction behavior and binding properties of excipients. However, each excipient has its own compaction behaviour and may change the compaction properties of the powder mixture and influence the strength of tablets or other tableting properties.

During tablet compaction, there are some factors that influence powder compactibility. One of such important factors is the mechanism of volume reduction which involves elastic and plastic deformation, particle fragmentation and brittle fracture $[3,4]$.

Heckel equation has been used to study the compaction behavior of different excipients [5]. It describes the relationship between the porosity of the tablet and the compression pressure used. As the majority of formulated tablets consist of mixtures of more than one powder, it is important to be familiar with the properties of the tablets obtained by compression of powder mixtures in addition to the individual properties of the tablet components. This is vital because interactions between the materials may occur during the compaction process.

Many studies have been carried out to investigate the relationship between tensile strength and the properties of excipients in a tablet, including compaction behavior, porosity, particle size, particle shape, etc [59]. Many researchers have also attempted to investigate and predict the strength of binary tablets based on its individual materials, and a range of results reported. It has been found that the tensile strength of lactose and dibasic calcium phosphate dihydrate tablet was directly related to the proportions of its single components. A similar relationship has been found for a mixture of sodium chloride and polyethylene [10]. The mixtures of dicalcium phosphate dihydrate and phenacetin lead to the formation of tablet with higher tensile strength than the tablets of their individual materials [11]. However, the addition of some other materials produced tablets of lower strength than the tablets of individual materials [12].

To some extent, the production of multilayered tablets in sustained-release formulation faces the same challenges as encountered by binary mixture tablets with regard to their mechanical strength [13]. . Understanding the mechanical strength and tableting behaviour of such tablets will prevent wastage during the manufacturing process and allow the drug to be released as intended. Therefore, the aim of this study was to carry out a study on the deformation behavior of plastic/plastic, brittle/plastic deformation and brittle/brittle fracture type of excipients and their effect on the mechanical strength of their binary mixtures and bilayer tablets. 


\section{EXPERIMENTAL}

\section{Materials}

Plastic deforming excipients, microcrystalline cellulose (Vivapur $200^{\circledR}$ ) and ethyl cellulose, were purchased from JRS, Germany and Sigma-Aldrich, USA, respectively, while brittle fracture materials, anhydrous lactose and dextrate (Emdex®), were supplied by Fluka, Germany and JRS, Germany, respectively. Magnesium stearate, used as a lubricant, was obtained from Sigma-Aldrich, Germany.

\section{Determination of powder density}

The true densities of the materials were measured by helium pycnometry (Micromeritics, AccuPyc 1330, USA). The powder materials were dried in an oven at 40 ${ }^{\circ} \mathrm{C}$ until they were dried properly and constant weight was achieved before they were used in tableting, to prevent the influence of moisture. The bulk densities of the powders were obtained from $100 \mathrm{~g}$ of samples filled in $100 \mathrm{ml}$ cylinder and bulk density was calculated from the ratio of powder weight to the volume of the powder in the cylinder. Tap densities were measured by using the similar weights of powder samples in $100 \mathrm{ml}$ cylinder and tapping the cylinder using a tap density tester (Erweka, Germany). Six measurements were made and their mean calculated.

\section{Assessment of particle size distribution and particle shape}

Samples (100 g each) of microcrystalline cellulose, ethyl cellulose, lactose anhydrous and dextrate' were accurately weighed on an analytical balance (Shimadzu AUY 220, Japan) and sieved for 30 minutes using a mechanical sieve shaker (Endecotts Octagon Digital, England). Particle sizes of each excipient in the range of $200-355 \mu \mathrm{m}$ were used to prepare the tablet formulations. The morphology of the powder materials and their compacts were determined by scanning electron microscopy (1450VP, LEO,
Germany). Each sample was placed on a thin plate and kept into the oven at $37^{\circ} \mathrm{C}$ for 30 min to minimize their moisture interference with scanning objects. The plate was sputtercoated with gold using an iron sputter (Bio Rad SC 500,USA) before it was scanned.

\section{Determination of flowability}

Two parameters were used to describe the flowability of the powders namely Hausner ratio and Carr's index. Bulk and tap density data were used to compute powder flowability according to Eqs 1 and 2.

$H R=\frac{T D}{B D}$

$C I=\frac{T D-B D}{T D} \times 100 \%$

where HR is Hausner ratio, $\mathrm{Cl}$ is Carr's Index, BD is bulk density of the powder, and TD is powder tapped density.

\section{Preparation of tablets from individual excipients}

The compact of the individual materials was prepared by compressing $600 \mathrm{mg}$ of powder using a custom-made $12 \mathrm{~mm}$ stainless steel punch and die with Universal testing machine (Instron 5567, USA). Magnesium stearate (1 $\%$ ) suspended in acetone was used to lubricate the die prior to compression only for lactose anhydrous and dextrate. The tablets were compressed at 44.2, 61.9, 88.4, 106.1, 132.7 and 159.2 MPa. Compression and decompression speed was set at $5 \mathrm{~mm} / \mathrm{s}$. The compacts were stored at relative humidity of $60 \pm 5 \%$ and $25 \pm 2{ }^{\circ} \mathrm{C}$ for at least $96 \mathrm{~h}$. Six tablets were made from each material and compression pressure.

\section{Preparation of binary tablets}

A series of binary mixtures of microcrystalline cellulose/ethyl cellulose, microcrystalline cellulose/dextrate, microcrystalline cellulose/ lactose anhydrous and dextrate/lactose 
anhydrous were made in the following mass ratios of $0 / 100,30 / 70,50 / 50,70 / 30,100 / 0$ $\mathrm{w} / \mathrm{w}$. For each binary mixture, $100 \mathrm{~g}$ was mixed for 30 min using a three dimensional tumbling mixer (SYH-1L, Minhua, China). Tablets/compacts of $600 \mathrm{mg}$ of each mixture were compressed in a $12 \mathrm{~mm}$ die tabletting machine as described earlier.

\section{Preparation of bilayer tablets}

Bilayer tablets (600 mg) were prepared using a series of powder combinations of MCC/ethyl cellulose, MCC/dextrate, MCC/lactose anhydrous and dextrate/lactose anhydrous using the same mass ratios as used for preparing binary mixture tablets. The first layer of powder was manually poured into the $12 \mathrm{~mm}$ die and precompressed at $0.27 \mathrm{MPa}$. Thereafter, the other powder was poured into the die to make the second layer The powder bed of the two layers was then compressed at $44.21,61.9,88.42$, 106.12, 132.67 and 159.2 MPa. A mixture of $1 \%$ magnesium stearate in acetone was used to lubricate the die in advance for lactose anhydrous and dextrate. The compression and decompression speed was set at $5 \mathrm{~mm} / \mathrm{s}$. The tablets were handled as described for binary tablets.

\section{Determination of the true density of powder mixtures}

The true density of the various mixtures was determined from the true density of the individual powder materials according to the rule of mixing using Eq 3 [14].

$\frac{1}{\rho m}=\frac{\xi 1}{\rho 1}+\frac{\xi^{2}}{\rho 2}$

where $\rho m, \rho 1$ and $\rho 2$ are the true densities of the mixture, and the component powders 1 and 2 , respectively, while $\xi 1$ and $\xi 2$ are the weight fractions of component powders 1 and 2 , respectively.

\section{Evaluation of the mechanical properties of tablets}

Tablet tensile strength $(\sigma t)$ was calculated as in Eq 4 [15].

$\sigma t=\frac{2 F}{\pi d t}$

where $F$ is the force required to fracture the tablet, and $d$ and $t$ are the diameter and thickness of the tablet, respectively.

\section{Determination of the relative density and porosity of tablets}

The relative density of the tablets was calculated by dividing the apparent density of the tablets with true density of the individual powders. The porosity of the tablets was obtained from the values of relative densities, weight of tablets and dimensions measurements as in Eqs 5 - 7 [16]:

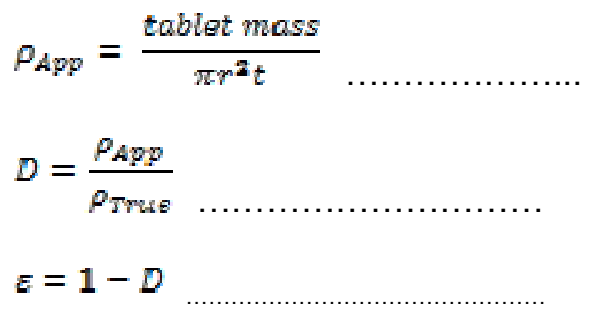

where $\mathrm{D}, \rho_{\text {App }}, \rho_{\text {True, }} r$ and $t$ are the relative, apparent and true densities, and radius and thickness of the compact, respectively.

\section{Data analysis}

The distribution of strength variable, based on compaction pressure and mixture ratio, was examined using Shapiro test. The strength of binary and bilayer tablets are presented as mean \pm SD. Independent sample test was used to assess difference in strength between tablet types (i.e., binary and bilayer). One-way ANOVA was used to determine significant difference in the strength of the tablet strength according to compaction pressure and mixture ratio. Three-way ANOVA was conducted to test the 
significance of the main parameters and possible interactions among the three variables (i.e., type of tablet, compaction pressure and mixture ratio).

\section{RESULTS}

\section{Physicochemical properties of the powders}

Bulk and tap densities, Hausner ratio $(\mathrm{HI})$ and Carr's index $(\mathrm{Cl})$ of the individual powders are shown in Table 1. The flowability of the materials were assessed based on the values of $\mathrm{HI}$ and $\mathrm{Cl}$ and are also shown in Table 1.

\section{Tensile strength - porosity relationship}

Figure 2(a) shows the effect of compression pressure on the tensile strength of the individual excipients while Table 2 shows the tensile strengths (MPa) of tablets formulated with different blends of excipients.

Table 1: Physicochemical properties of individual powders (mean \pm SD)

\begin{tabular}{lllllll}
\hline Powder & $\begin{array}{l}\text { True density } \\
\text { (g/ml) }\end{array}$ & $\begin{array}{l}\text { Bulk } \\
\text { density } \\
\mathbf{( g / m l )}\end{array}$ & $\begin{array}{l}\text { Tap } \\
\text { density } \\
\mathbf{( g / m l )}\end{array}$ & $\begin{array}{l}\text { Hausner } \\
\text { ratio }\end{array}$ & $\begin{array}{l}\text { Carr's } \\
\text { index }\end{array}$ & Flowability \\
\hline MCC $^{*}$ & $1.696 \pm 0.003$ & $0.395 \pm 0.09$ & $0.46 \pm 0.11$ & 1.165 & 14.1 & Good \\
EC $^{* *}$ & $1.278 \pm 0.003$ & $0.364 \pm 0.13$ & $0.43 \pm 0.09$ & 1.190 & 16 & Fair \\
Dextrate & $1.729 \pm 0.002$ & $0.667 \pm 0.07$ & $0.71 \pm 0.12$ & 1.060 & 5.7 & Excellent \\
Lactose & $1.694 \pm 0.008$ & $0.677 \pm 0.15$ & $0.76 \pm 0.16$ & 1.129 & 11.4 & Good \\
\hline
\end{tabular}

${ }^{*}$ Microcrystalline cellulose; ${ }^{* *}$ ethyl cellulose
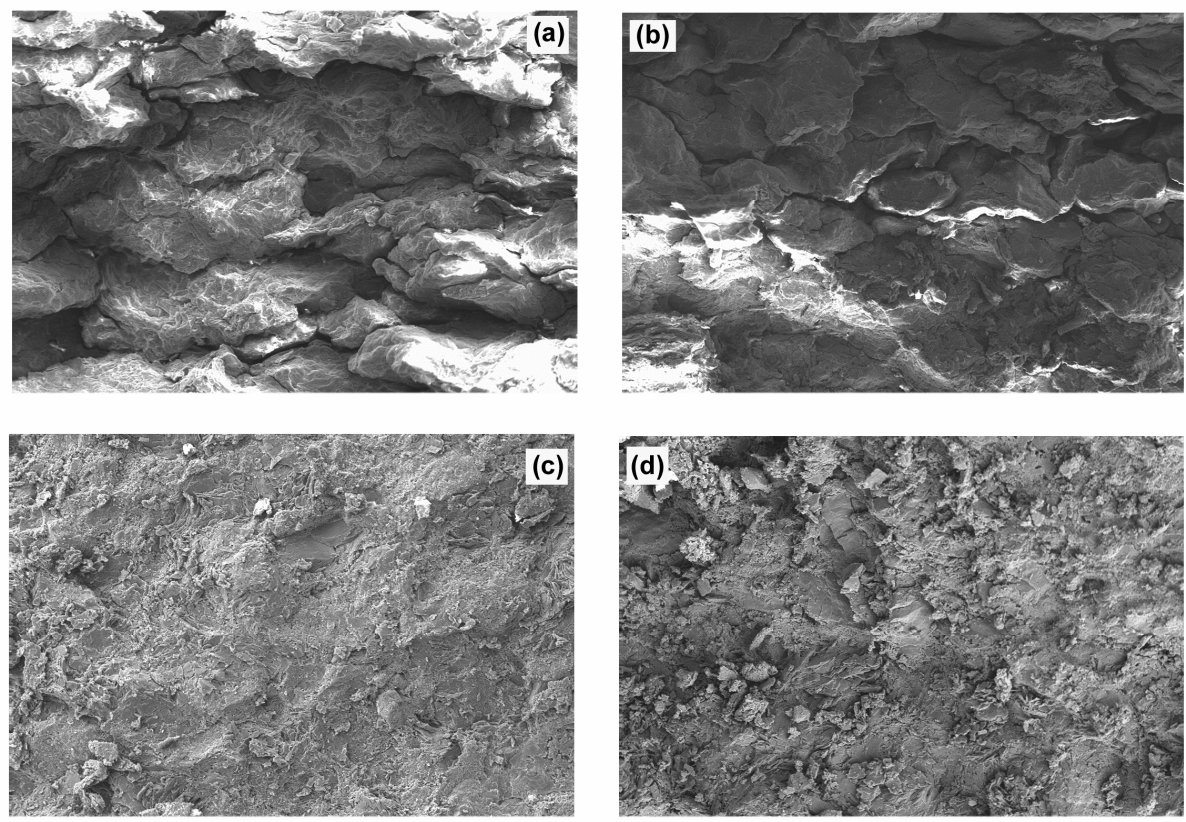

Fig 1: (a) Scanning electron micrographs (SEM) of cross-section of 50/50 MCC/ethyl cellulose binary tablet, (b) 50/50 MCC/ethyl cellulose bilayer tablet, (c) 50/50 dextrate/lactose binary tablet, and (d) 50/50 dextrate/lactose bilayer tablet. (Note: x 100 magnification) 


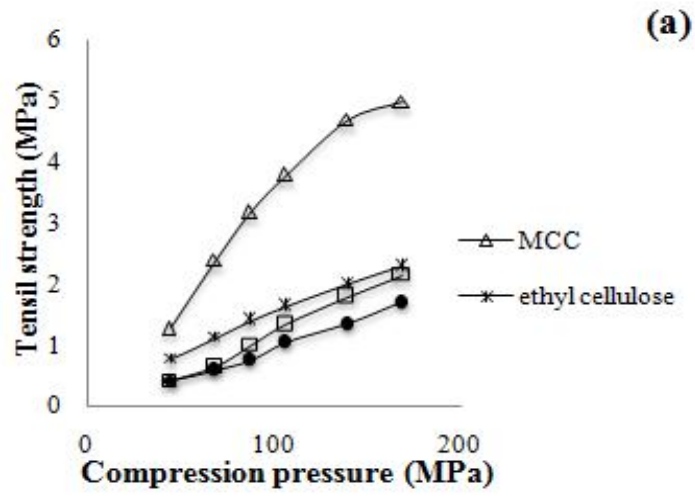

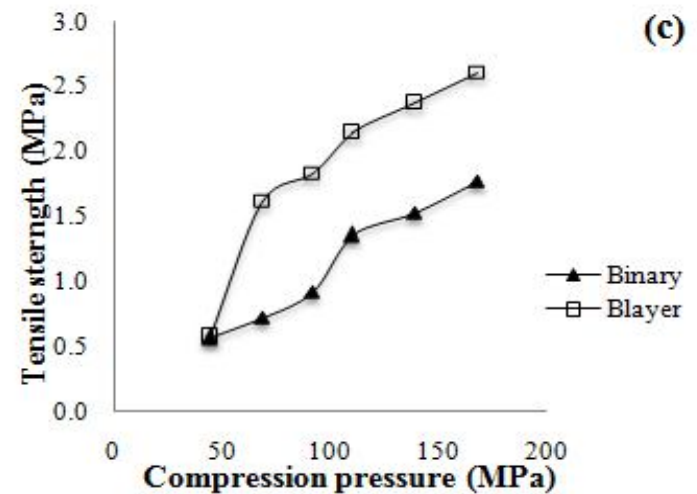

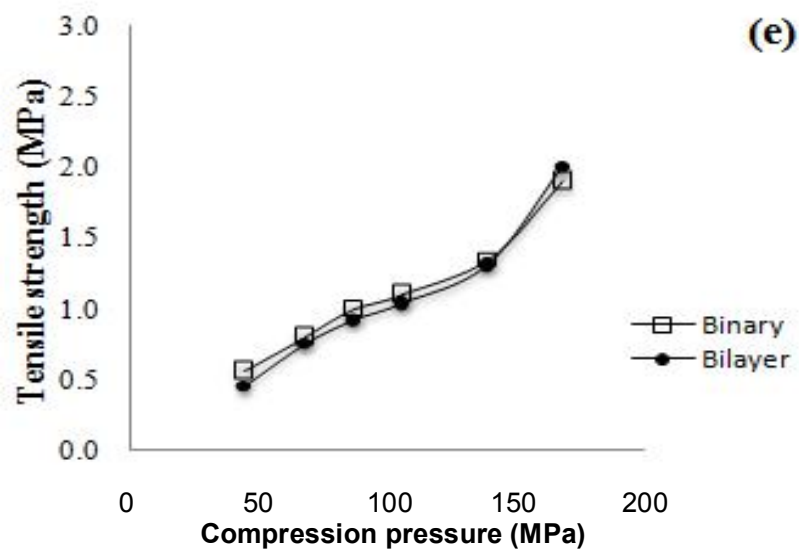

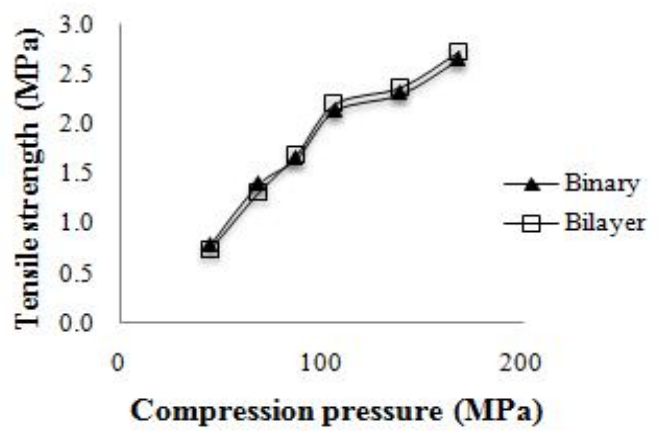

(b)

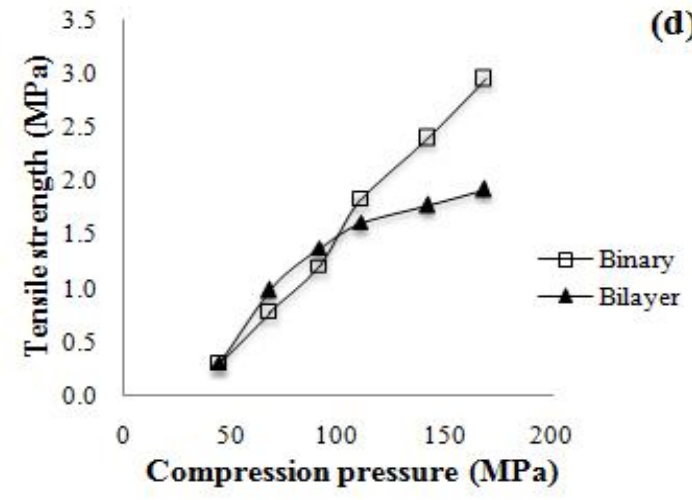

(e)

(d) 
Amin et al

\begin{tabular}{llllll}
\hline $\begin{array}{l}\text { Excipient ratio } \\
\text { MCC/EC }\end{array}$ & $\begin{array}{l}\text { Tensile } \\
\text { Strength } \\
\text { (MPa) }\end{array}$ & SD & $\begin{array}{l}\text { Excipient ratio } \\
\text { MCC/Dextrate }\end{array}$ & $\begin{array}{l}\text { Tensile } \\
\text { Strength } \\
\text { (MPa) }\end{array}$ & SD \\
\hline $0 / 100$ & 1.4841 & 0.047 & $0 / 100$ & 1.1514 & 0.051 \\
$30 / 70$ & 1.6497 & 0.055 & $30 / 70$ & 1.1430 & 0.046 \\
$50 / 50$ & 1.7737 & 0.068 & $50 / 50$ & 1.4663 & 0.074 \\
$70 / 30$ & 1.9712 & 0.097 & $70 / 30$ & 1.8044 & 0.087 \\
$100 / 0$ & 3.3401 & 0.151 & $100 / 0$ & 3.3401 & 0.156 \\
\hline
\end{tabular}

(a)

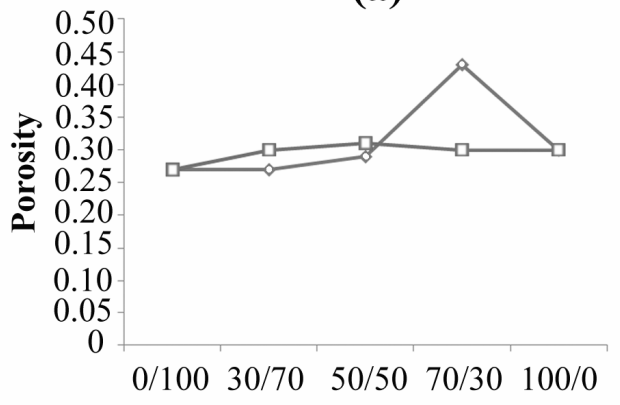

Excipient blend ratio (MCC/EC)

(c)

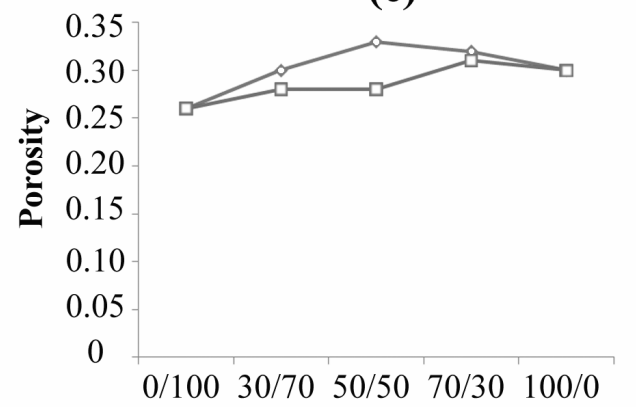

Excipient blend ratio (MCC/Lactose)

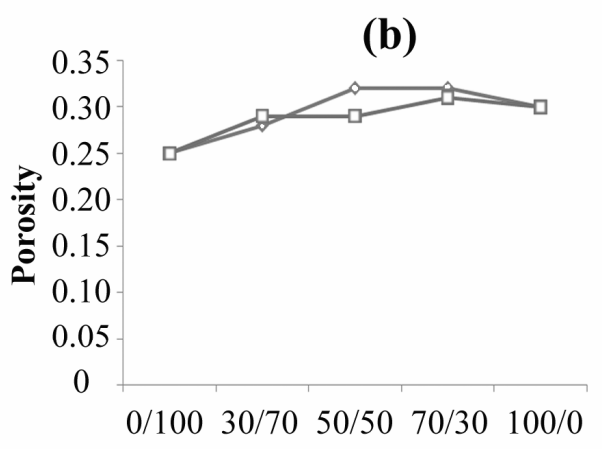

Excipient blend ratio (MCC/Dext)

(d)

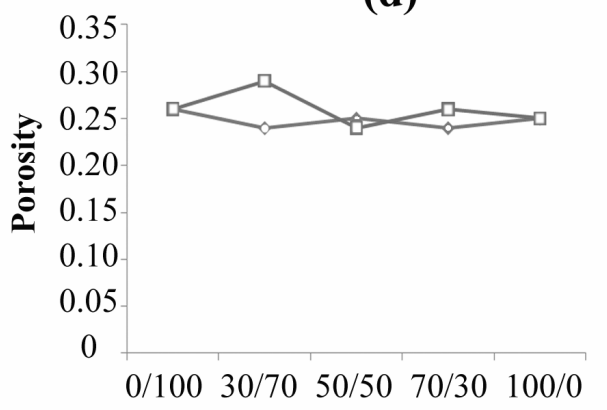

Excipient blend ratio (Dext/Lactose)

Fig 3: Effect of excipient mixture ratio on the porosity of binary $(\triangleleft)$ and bilayer $(\square)$ tablets compressed at $61.9 \mathrm{MPa}$

Figures 2(b), 2(c), 2(d) and 2(e) show effect of compression pressure on the tensile strength of binary and bilayer tablets (50/50 excipient blend ratio) formulated with MCC/EC (plastically deforming materials), MCC/dextrate and $\mathrm{MCC} /$ lactose (brittle fracture materials), respectively. There was no significant difference between the binary and bilayer tablets $(p>0.05)$ in the case of MCC/lactose (Fig 2(e).

Figure 3 shows the effect of excipient blend ratio on the porosity of binary and bilayer tablets compressed at $61.9 \mathrm{MPa}$. Particles below $200 \mu \mathrm{m}$ showed less flowability, compared to larger particles. The particles of microcrystalline cellulose were irregular in shape and the larger particles were more spherical than the smaller particles. Similarly, large ethyl cellulose particles were also more spherical than the smaller particles which more elongated and irregular in shape. Comparatively, dextrate particles were also spherical in shape but of uniform size with some particles showing surface roughness. Anhydrous lactose particles were irregular in shape and small fractured areas were seen on the surface of the larger particles which looked more regular than the smaller ones. 
There was no significant $(p>0.05)$ difference between binary and bilayer tablets, as Fig 2(b) shows, even when compression pressure was changed. Figure 2(c) and 2 (d) represent a combination of two different deformation behaviors (i.e., plastic and brittle deformation). There was a significant ( $p<$ 0.05 ) difference between the tensile strength of tablets of both combinations. No consistent relationship was seen between tablet porosity and excipient blend ratio for both binary and bilayer tablets in all plots. Although there was a significant difference in porosity between binary and bilayer tablets at all excipient blend ratios, the porosity at 50/50 blend ratio for MCC/ethyl cellulose and dextrate/lactose was almost the same, as shown in Figure 3(a) and (d).

\section{DISCUSSION}

Different values for Hausner equation and Carr's index have been reported [16-20] for MCC and lactose. But only this study has found the values of Hausner ratio and Carr's index for dextrate and ethyl cellulose. The flow characteristics of dextrate were excellent and this may be attributed to its uniform size and spherical shape. Microcrystalline cellulose and anhydrous lactose powders showed good flowability while ethyl cellulose exhibited fair flowability.

The mechanical strength of the tablets was influenced by relative humidity. Except ethyl cellulose, all the tablets exhibited maximum tensile strength at $52 \pm 5 \%$ relative humidity beyond which tensile strength increased when relative humidity decreased. This is because adsorbed water molecules lead to weaker interparticle forces. A multilayer of water may form on the surface of particles acting as a lubricant and leading to a reduction in frictional forces between particles, thereby decreasing tensile strength However, no specific relationship between tensile strength and relative humidity was obtained when ethyl cellulose tablet was investigated. This is because ethyl cellulose absorbs very little water from the atomsphere.

In Figure 1(a) it is difficult to differentiate between the two materials as both of them are plastically deformed. The dark clusters represent ethyl cellulose particles embedded in-between MCC particle. MCC particles were not completely deformed which may be due to the interference of ethyl cellulose particles when mixed with MCC particles. In Figure 1(b), just like the binary mixture of both materials, MCC particles which constitutes the lower layer, showed greater deformation than ethyl cellulose particles (upper layer). This was probably caused by the absence of any interference from ethyl cellulose particle as well as the excellent compressibility property of MCC. In Figure 1(c) and (d), it is difficult to differentiate between both materials (dextrate and lactose) as both had undergone a similar type of deformation upon compression, The melted dark areas represent dextrate particles which have regular, spherical morphology while the porous light areas represent anhydrous lactose which has undergone excessive fragmentation under compression. The use of high compression pressure might have resulted in greater deformation affinity and/or fragmentation of single particles, thus making it difficult to detect differences in surface texture.

In Figure 2(a), it can be seen that the tensile strength of all the tablets increased as compression pressure increased. Among plastic powders, MCC had greater tensile strength than ethyl cellulose. This is because MCC particles showed greater plastic deformation than ethyl cellulose at the same compression pressure. The density of plastic powders approaches zero porosity faster, resulting in larger areas of interparticulate bonding and hence, stronger tablets. Moreover, the less regular the shape of particles, the higher the compactability. On the other hand, lactose had higher tensile strength than dextrate, the reason being that lactose experienced greater particle 
fragmentation, generating more new particles and hence additional new sites for bonding.

Both MCC/ethyl cellulose and dextrate/ lactose combinations exhibit the same compression behavior (i.e., plastic deformation or fragmentation). However, the powder mixtures are considered as a whole powder bed which is not the case when MCC was mixed with the brittle materials dextrate or lactose even in 50/50 ratio. This may be due to the fragmented particles of dextrate and lactose filling the voids between MCC particles, thus interfering with the bonding capability of the particles which in turn reduced the tensile strength of the tablets [9]. The porosity of all the materials decreased when the compression pressure increased. The particles of each powder material might have rearranged themselves in the die leading to a closer packing structure, thus minimizing the porosity of its powder bed and hence, a coherent compact when compressed at increasing pressure. In Figure 3 , no constant relationship was seen between the porosity of the tablet and the composition of both binary mixtures and bilayer tablets.

\section{CONCLUSION}

The tensile strength of plastic deforming excipients is higher than that of other excipients which consolidate by fragmentation and tablet strength decreased in the following order: MCC > ethyl cellulose $>$ anhydrous lactose $>$ dextrate. With regard to binary mixture and bilayer tablets, this study showed that only those combinations with two similar consolidation behaviours (i.e. plastic/plastic or brittle/brittle) at 50/50 composition ratio exhibited similar tensile strength. This understanding should assist pharmaceutical formulators in the development of suitable bilayer tablets.

\section{ACKNOWLEDGEMENT}

The authors would like to thank Ministry of Science, Technology \& Innovation, Malaysia
(IRPA 09-02-02-0095EA239) for funding this work.

\section{REFERENCES}

1. Jivarji M, Martini LG, Thomson CM. An overview of the different excipients useful for the direct compression of tablets. Pharm. Sci. Technol. 2008; 3: 58-63.

2. Kasa P, Bajdik J, Zsigmond Z, Pintye-Hodi K. Study of the compaction behavior and compressibility of binary mixtures pharmaceutical excipients during direct compression. Chem. Eng. Process. 2009; 48(4): 859-863.

3. Nystrom C, Alderborn G. The compactability of pharmaceutical powders in Sandell E. Industrial aspects of pharmaceutics. Stockholm: Swedish Pharmaceutical Press; 1993; pp 129-152.

4. Uhumwangho MU, Okor RS, Adogah JT. Potential of carnauba wax in ameliorating brittle fracture during tableting. Pak. J. Pharm Sci., 2009; 22(1): 58-61.

5. Amin MCl, Fell JT. Tensile strength and bonding in compacts: A comparison of diametral compression and three-point bending for plastically deforming materials. Drug Dev. Ind. Pharm., 2002; 28(7): 809-813.

6. Sheikh-Salem M, Fell JT. Compaction characteristics of mixtures of materials with dissimilar compaction mechanisms. Int. J. Pharm. Technol. Prod. Manuf., 1981; 21: 19-22.

7. Sebhatu T, Alderborn G. Relationships between the effective interparticulate contact area and the tensile strength of tablets of amorphous and crystalline lactose of varying particle size. Eur. J. Pharm. Sci., 1999; 8: 235-242.

8. Veen BV, Maarschalk KVD, Bolhuis GK, Zuurman K, Frijlink HW. Tensile strength of tablets containing two materials with a different compaction behavior Int. J. Pharm., 2000; 203(1-2): 71-79.

9. Nikolakakis I, Pilpel N. Effect of particle size and particle shape on the tensile strengths of powders. Powder Technol., 2001; 45(1): 7982.

10. Rubinstein $M H$, Jackson IM. Stress relaxation behavior of compacts of sodium chloride anpolyethylene. Int. J. Pharm., 1987; 36: 99104.

11. Newton JM, Cook DT, Hollebon CE. The strength of tablets of mixed components. J. Pharm. Pharmacol., 1977; 29: 247-248.

12. Sheikh-Salem M, Alkaysi $H$, Fell JT. The tensile strength of tablets of binary mixtures lubricated with magnesium stearate. Drug Dev. Ind. Pharm., 1988; 14: 895-903.

13. Wu CY, Seville JPK. A comparative study of compaction properties of binary and bilayer tablets. Powder. Technol., 2009; 189(2): 285294. 
14. Wu CY, Best SM, Bentham AC, Hancock BC, Bonfield $W$. Predicting the tensile strength of compacted multi-component mixtures of pharmaceutical powders, Pharm. Res., 2006; 23: 1898-1905.

15. Fell JT, Newton JM. Determination of the tablet strength by the diametrical compression test. J. Pharm. Sci., 1970; 59: 688-691.

16. Kumar V, Reus-Medina DLL, Yang D. Preparation, characterization, and tableting properties of a new cellulose-based pharmaceutical aid. Int. J. Pharm., 2002; 235(1-2): 129-140.

17. Wu J, Ho $H$, Sheu MT. A statistical design to evaluate the influence of manufacturing factors on the material properties and functionalities of microcrystalline cellulose. Eur. J. Pharm. Sci., 2001; 12(4): 417- 425.

18. Martino $P$, Joiris E, Martelli S. Particle interaction of lubricated or unlubricated binary mixtures according to their particle size and densification mechanism. Farmaco., 2004; 59(9): 747-758.

19. Sinka IC, Schneider LCR, Cocks ACF. Measurements of the flow properties of powders with special reference to die fill. Int. J. Pharm., 2004; 280(1-2): 27-38.

20. Schneider LCR, Sinka IC, Cocks ACF. Characterization of the flow behavior of pharmaceutical powders using a model dieshoe filling system. Powder Technol., 2006; 173(1): 59-71. 